\title{
Association Between Neutrophils and Renal Impairment of Rheumatoid Arthritis: A Retrospective Cross-sectional Study
}

peidan yang

Guangzhou University of Chinese Medicine https://orcid.org/0000-0001-8027-7074

Si-Min Lin

Guangzhou University of Chinese Medicine

\section{Zhi-Xin Chen}

South China Agricultural University College of Economics and Management

Min-Ying Liu

Guangzhou University of Chinese Medicine

Qing-Ping Liu

Guangzhou University of Chinese Medicine

Chang-Song Lin

Guangzhou University of Chinese Medicine

\section{Cong-Qiu Chu}

Oregon Health \& Science University - West Campus

Qiang Xu ( $\nabla$ fjksg@163.com )

Guangzhou University of Chinese Medicine

\section{Research article}

Keywords: Neutrophil, Renal impairment, Rheumatoid arthritis, Risk factors

Posted Date: July 27th, 2020

DOI: https://doi.org/10.21203/rs.3.rs-46097/v1

License: (c) (i) This work is licensed under a Creative Commons Attribution 4.0 International License. Read Full License

Version of Record: A version of this preprint was published at Immunity, Inflammation and Disease on May 25th, 2021. See the published version at https://doi.org/10.1002/iid3.459. 


\section{Abstract \\ Objective}

Whether neutrophil could be a risk factor of renal impairment in rheumatoid arthritis (RA) remains unclear. Therefore, we aimed to investigate the prevalence of renal impairment in RA and determine its correlation with neutrophils.

\section{Methods}

We retrospectively investigated renal function of 602 RA patients in the First Affiliated Hospital of Guangzhou University of Traditional Chinese Medicine by estimated glomerular filtration rate (GFR). Potential risk factors for renal dysfunction were collected in all RA patients. We used univariate and multivariate logistic regression analysis to evaluate association between neutrophils and renal impairment.

\section{Results}

A total of 89 cases $\left(14.8 \%\right.$ ) had renal impairment with GFR $<60 \mathrm{ml} / \mathrm{min} / 1.73 \mathrm{~m}^{2}$, and 75 cases $(84.3 \%)$ were female. Compared to RA patients with normal renal function, age, white blood cell count, serum levels of triglyceride, uric acid, C-reactive protein level, erythrocyte sedimentation rate, Cystatin-C, and creatinine in those with renal impairment increased, but red blood cell count and hemoglobin level decreased (all $p<0.05$ ). Adjusted for numerous potential confounders, multivariate analysis indicated that neutrophils $>7.5 \times 10^{\wedge} 9 / \mathrm{L}(\mathrm{OR}=1.7,95 \% \mathrm{Cl}: 1.03$ to 2.98$)$, hemoglobin $<120 \mathrm{~g} / \mathrm{L}(\mathrm{OR}=2.4,95 \% \mathrm{Cl}$ : 1.360 to 4.281$)$, and uric acid $>360 \mathrm{umol} / \mathrm{I}(\mathrm{OR}=6.1,95 \% \mathrm{Cl}: 3.71$ to 10.10$)$ significantly correlated with a higher risk of renal impairment.

\section{Conclusions}

Neutrophil count $>7.5 \times 10^{\wedge} 9 / \mathrm{L}$ may be associated with a high risk of renal impairment in RA. Prospective studies are needed to verify our results.

\section{Introduction}

Renal impairment, defined by an estimated glomerular filtration rate (GFR) $<60 \mathrm{ml} /$ minute $/ 1.73 \mathrm{~m}^{2}$ for at least 3 months [1], was more likely to occur in patients with rheumatoid arthritis (RA) [2]. Previous studies showed that the prevalence of renal damage in RA patients was between $5 \%$ and $50 \%[3,4]$ in different cohorts. Severe renal impairment inevitably brings physical injury and economic burden as well as death $[5,6]$. It was reported that the mortality rate in RA patients with kidney damage was significantly 
increased when compared to patients with normal renal function $[7,8]$. The leading causes of death amongst RA patients with renal impairment were chronic infection[3, 9], inflammatory response [10, 11], severe drug adverse reactions (cyclosporin A, etanercept, COX-2 inhibitor, nonsteroidal anti-inflammatory drugs (NSAIDs) and vasculitis [12]. A meta-analysis revealed that a significantly increased risk of kidney damage in patients with RA, with a pooled risk ratio(RR) of 1.52, and a $95 \%$ confidence interval (Cl) of 1.28 to 1.80 [13]. Consequently, it is essential to learn more about possible risk factors for renal insufficiency in patients with RA. It is well known that uric acid (UA) levels [4], inflammation-related indicators such as erythrocyte sedimentation rate (ESR) [2], and cardiovascular risk factors $[3,14,15]$ such as hypertension, dyslipidemia, diabetes, and obesity are linked to kidney damage. However, whether neutrophils increase the higher risk of kidney damage in RA patients is currently unclear. Therefore, we aimed to investigate the prevalence of renal impairment in RA and determine its correlation with neutrophils.

\section{Methods}

\section{Study design and patients}

A total of 685 data from the original database of the First Affiliated Hospital of Guangzhou University of Chinese Medicine between September 2018 and September 2019, were screened in our cross-sectional analysis. Patients in this dataset should met the classification criteria of the American College of Rheumatology for RA 2010[16] and were over 18 years of age. We therefore excluded 2 patients < 18 years old and 81 patients without critical data for analysis, 602 were available for investigation. The inclusion process is shown in Fig. 1. Written informed consent was acquired from all participants. We followed the principles of the Declaration of Helsinki and received approval from the Ethics Committee of the First Affiliated Hospital of Guangzhou University of Traditional Chinese Medicine (No.

ZYYECK[2019]040).

\section{Data Collection}

The categories of data collected were as follows: (1) General demographics: sex, age (years), RA durations (months), current alcohol and cigarette use; (2) Prescription of drugs for RA: steroids, disease modifying anti-rheumatic drugs (DMARDs); nonsteroidal antiinflammatory drugs (NSAIDs); (3) Levels of common cardiovascular risk factors: hypertension, diabetes mellitus, total cholesterol (TC), triglycerides (TG), high-density lipoproteins (HDL), and low-density lipoproteins (LDL); (4) Inflammation-related indicators: erythrocyte sedimentation rate (ESR) and C-reactive protein levels (CRP); (5) Laboratory indicators: cell counts of white blood cell (WBC), lymphocyte (LYM), neutrophil, neutrophil to lymphocyte ratio (NLR), red blood cells (RBC), and hemoglobin (HGB) levels; (6) Uric acid (UA) levels; (7) Biochemical markers for RA: rheumatoid factor (RF) and anti-cyclic citrullinated peptide (anti-CCP); (8) Renal function indicators: GFR, serum creatinine (SCr), and cystatin C (CysC). Following the 2013 Kidney Disease: Improving Global Outcomes (KDIGO) guidelines, the Chronic Kidney Disease-Epidemiology Collaboration 
(CKD-EPI) equation involving SCr and CysC levels was used to calculate GFR. Patients with GFR< $60 \mathrm{ml} / \mathrm{min} 1.73 \mathrm{~m}^{2}$ were identified as having renal impairment regardless of kidney markers.

\section{Statistical analysis}

The normality of the data was evaluated by the Shapiro-Wilk test [17]. Quantitative data were presented as mean \pm standard deviation (S.D.) or median (Interquartile range, IQR), and qualitative data as number and percentage. Categorical data was assessed by the Chi-square test or Fisher exact test, while continuous data was appraised by the Mann-Whitney test or Student T-test. To analyze factors significantly associated with the RA with renal impairment, we employed univariate and multivariate logistic regression analysis. Features with significant significance and clinical relevance in univariate analysis were introduced into the multivariate logistic model. Results were presented as the odds ratio (OR) and their $95 \% \mathrm{Cl}$. All analyses in our study used Stata (version 15.0) and the threshold for statistical significance was set to 0.05 .

\section{Results}

\section{Demographic and Clinical Characteristics}

Of 602 RA patients, $89(14.8 \%)$ had renal damage with GFR $<60 \mathrm{ml} /$ minute $/ 1.73 \mathrm{~m}^{2}$, and $513(85.2 \%)$ had normal renal function with GFR $>60 \mathrm{ml} /$ minute $/ 1.73 \mathrm{~m}^{2}$. Among renal damage group, $75(84.3 \%)$ were female, and $31(34.8 \%)$ suffered from Hypertension and 12(13.5\%) had diabetes mellitus. Compared to RA patients with normal renal function, RA patients in the renal impairment group had a relatively older age (median \pm IQR: $61 \pm 14.5$ vs $59 \pm 15, p=0.027$ ), lower RBC count (median \pm IQR:3.70 \pm 0.89 vs $3.99 \pm 0.61$, $p=0.001)$ and hemoglobin level (median \pm IQR:103 \pm 29 vs $110 \pm 33, p=0.006)$, higher WBC count (median \pm IQR:7.36 \pm 4.32 vs $6.84 \pm 3.08, p=0.035$ ), TG levels (median \pm IQR:1.11 \pm 0.445 vs $0.97 \pm 0.58, p$ $=0.003$ ), ESR (median \pm IQR: $55 \pm 50$ vs $42 \pm 40.5, p=0.019), C R P$ (median \pm IQR:36.9 \pm 61.4 vs $23.3 \pm$ 43.18, $p=0.016$ ), UA levels (median \pm IQR:358 \pm 172 vs $270 \pm 110.5, p<0.001)$, Scr (median \pm IQR: $88 \pm$ 25.5 vs $59 \pm 18, p<0.001$ ), and CysC (median \pm IQR: $1.50 \pm 0.42$ vs $0.97 \pm 0.26, p<0.001$ ). Table 1 and Fig. 2 showed detailed information on the demographic and clinical characteristics of the RA patient cohort. 
Table 1

Demographic, clinical, cardiovascular, and inflammatory factor of rheumatoid arthritis with or without renal impairment

\begin{tabular}{|c|c|c|c|}
\hline & $\begin{array}{l}\text { GFR }<60 \\
(n=89)\end{array}$ & $\begin{array}{l}\text { GFR } \geq 60 \\
(n=513)\end{array}$ & $\mathbf{P}$ \\
\hline Age, years, median \pm IQR & $61(54-68.5)$ & $59(50-65.5)$ & $0.027 *$ \\
\hline Women sex, n (\%) & 75(84.3) & $400(78)$ & 0.206 \\
\hline $\begin{array}{l}\text { RA Duration, months, } \\
\text { median } \pm \text { IQR }\end{array}$ & $96(36-138)$ & $72(24-120)$ & 0.066 \\
\hline Hypertension, n (\%) & $31(34.8)$ & $147(28.7)$ & 0.258 \\
\hline Diabetes mellitus, $\mathrm{n}(\%)$ & $12(13.5)$ & $62(12.1)$ & 0.727 \\
\hline Current drinking, $\mathrm{n}(\%)$ & $2(2.2)$ & $16(3.1)$ & 0.998 \\
\hline Current smoker, n (\%) & $8(9)$ & $46(9)$ & 0.999 \\
\hline $\begin{array}{l}\text { White blood cell, } 10^{\wedge} 9 / \mathrm{L} \\
\text { median } \pm \text { IQR }\end{array}$ & 7.36(5.74-10.06) & $6.84(5.43-8.51)$ & $0.035^{\star}$ \\
\hline $\begin{array}{l}\text { Lymphocyte, } 10^{\wedge} 9 / \mathrm{L} \\
\text { median } \pm \text { IQR }\end{array}$ & $1.75(1.26-2.30)$ & $1.62(1.25-2.12)$ & 0.334 \\
\hline $\begin{array}{l}\text { Neutrophils, } 10^{\wedge} 9 / \mathrm{L} \text {, } \\
\text { median } \pm \text { IQR }\end{array}$ & $4.53(3.55-7.22)$ & $4.34(3.25-5.77)$ & 0.099 \\
\hline $\mathrm{NLR}, \%$, median \pm IQR & $2.96(1.98-4.30)$ & $2.55(1.89-3.75)$ & 0.116 \\
\hline $\begin{array}{l}\text { Red blood cell, 10^12 /L, } \\
\text { median } \pm \text { IQR }\end{array}$ & $3.70(3.36-4.25)$ & $3.99(3.70-4.31)$ & $0.001^{*}$ \\
\hline Hemoglobin, g/L, median \pm IQR & $103(87.5-116.5)$ & $110(98-121)$ & $0.006^{*}$ \\
\hline $\mathrm{TC}, \mathrm{mmmol} / \mathrm{I}$, median $\pm \mathrm{IQR}$ & $4.33(3.62-5.01)$ & $4.37(3.71-5.09)$ & 0.695 \\
\hline $\mathrm{LDL}, \mathrm{mmmol} / \mathrm{l}$, median $\pm \mathrm{IQR}$ & $2.72(2.19-3.40)$ & $2.86(2.25-3.48)$ & 0.539 \\
\hline
\end{tabular}

Note: values for categorical variables presented as $\mathrm{N}$ (percentage); values for continuous variables presented as mean \pm standard deviation (S.D) or median (interquartile range, IQR).

Abbreviation: RA, rheumatoid arthritis; RF, rheumatoid factor; anti-CCP, anti-cyclic citrullinated peptide antibody; NLR, neutrophil to lymphocyte ratio; TC, total cholesterol; LDL, low-density lipoprotein; HDL, high-density lipoprotein; TG, triglyceride; ESR, erythrocyte sedimentation rate; CRP, C reactive protein; DMARDs, disease modifying antirheumatic drugs; NASIDs: nonsteroidal anti-inflammatory drugs.

${ }^{*} \mathrm{p}<0.05,{ }^{* *} \mathrm{p}<0.001$ 


\begin{tabular}{|c|c|c|c|}
\hline & $\begin{array}{l}\text { GFR }<60 \\
(n=89)\end{array}$ & $\begin{array}{l}\text { GFR } \geq 60 \\
(n=513)\end{array}$ & $\mathbf{P}$ \\
\hline $\mathrm{HDL}, \mathrm{mmmol} / \mathrm{l}$, median $\pm \mathrm{IQR}$ & $1.13(0.89-1.40)$ & $1.20(0.95-1.49)$ & 0.158 \\
\hline $\mathrm{TG}, \mathrm{mmmol} / \mathrm{I}$, median \pm IQR & $1.11(0.91-1.41)$ & $0.97(0.74-1.32)$ & $0.003^{*}$ \\
\hline $\mathrm{ESR}, \mathrm{mm} / \mathrm{h}$, median \pm IQR & $55(26.5-76.5)$ & $42(22.5-63)$ & $0.019 *$ \\
\hline $\mathrm{CRP}, \mathrm{mg} / \mathrm{dL}$, median $\pm \mathrm{IQR}$ & $36.9(15.35-76.75)$ & 23.3(19.22-62.40) & $0.016^{*}$ \\
\hline Uric acid, umol/I, median \pm IQR & $358(269.5-441.5)$ & $270(214-324.5)$ & $<0.001^{* \star}$ \\
\hline Serum creatinine, median \pm IQR & $88(77.5-103)$ & $59(50-68)$ & $<0.001^{\star *}$ \\
\hline Cystatin C, mg/L, median \pm IQR & $1.50(1.33-1.75)$ & $0.97(0.85-1.11)$ & $<0.001^{\star *}$ \\
\hline RF positivity, n (\%) & $410(79.9)$ & $74(83.1)$ & 0.564 \\
\hline Anti-CCP seropositivity, $\mathrm{n}(\%)$ & $437(85.2)$ & $73(82)$ & 0.428 \\
\hline Steroid, n (\%) & $44(49.4)$ & $206(10.2)$ & 0.104 \\
\hline DMARDs, n (\%) & 15(16.9) & $84(16.4)$ & 0.878 \\
\hline NASIDs, n (\%) & $88(98.9)$ & $484(94.3)$ & 0.105 \\
\hline \multicolumn{4}{|c|}{$\begin{array}{l}\text { Note: values for categorical variables presented as } \mathrm{N} \text { (percentage); values for continuous variables } \\
\text { presented as mean } \pm \text { standard deviation (S.D) or median (interquartile range, IQR). }\end{array}$} \\
\hline \multicolumn{4}{|c|}{$\begin{array}{l}\text { Abbreviation: RA, rheumatoid arthritis; RF, rheumatoid factor; anti-CCP, anti-cyclic citrullinated peptide } \\
\text { antibody; NLR, neutrophil to lymphocyte ratio; TC, total cholesterol; LDL, low-density lipoprotein; HDL } \\
\text { high-density lipoprotein; TG, triglyceride; ESR, erythrocyte sedimentation rate; CRP, C reactive protein; } \\
\text { DMARDs, disease modifying antirheumatic drugs; NASIDs: nonsteroidal anti-inflammatory drugs. }\end{array}$} \\
\hline${ }^{\star} \mathrm{p}<0.05, * \star p<0.001$ & & & \\
\hline
\end{tabular}

\section{Bivariate logistic regression analysis}

Bivariate analysis was showed Table 2 and Fig. 3. Our analysis indicated that female $(\mathrm{OR}=0.523,95 \% \mathrm{Cl}$ : 0.318 to 0.367$)$, Neutrophil count $>7.5 \times 10^{\wedge} 9 / \mathrm{L}(\mathrm{OR}=2.314,95 \% \mathrm{Cl}: 1.310$ to 4.087$), \mathrm{NLR}>3.53$ (OR= 1.757, $95 \% \mathrm{Cl}: 1.104$ to 2.799$)$, Hemoglobin $<120 \mathrm{~g} / \mathrm{L}(\mathrm{OR}=2.413,95 \% \mathrm{Cl}: 1.418$ to 4.118$)$, and UA > $360 \mathrm{umol} / \mathrm{I}(\mathrm{OR}=6.052,95 \% \mathrm{Cl}: 3.708$ to 9.878$)$ were significantly associated with renal impairment in RA patients. 
Table 2

Univariate logistic regression analysis of renal impairment in rheumatoid arthritis

$\begin{array}{lll}\text { OR } & 95 \% \mathrm{Cl} & \mathrm{P}\end{array}$

Age

$<60$ years

Reference

$>60$ years

1.379

$0.876,2.172$

0.165

Sex

Male

Reference

Female

0.523

$0.318,0.867$

$0.011 *$

RA duration

$<10$ years

Reference

$>10$ years

1.379

$0.876,2.172$

0.165

Hypertension

No

Reference

Yes

1.331

$0.827,2.142$

0.241

Diabetes mellitus

No

Reference

Yes

1.134

$0.584,2.201$

0.711

Current drinking

No

Reference

Yes

0.714

$0.161,3.161$

0.657

Current smoking

No

Yes

1.003

$0.456,2.203$

0.995

Steroid

No

Reference

Abbreviation: RA, rheumatoid arthritis; NLR, Neutrophil to lymphocyte ratio; TC, total cholesterol; LDL, low-density lipoprotein; HDL, high-density lipoprotein; TG, triglyceride; ESR, erythrocyte sedimentation rate; CRP, C reactive protein; DMARDs, biological disease modifying antirheumatic drugs.

$p<0.05^{*}$ 


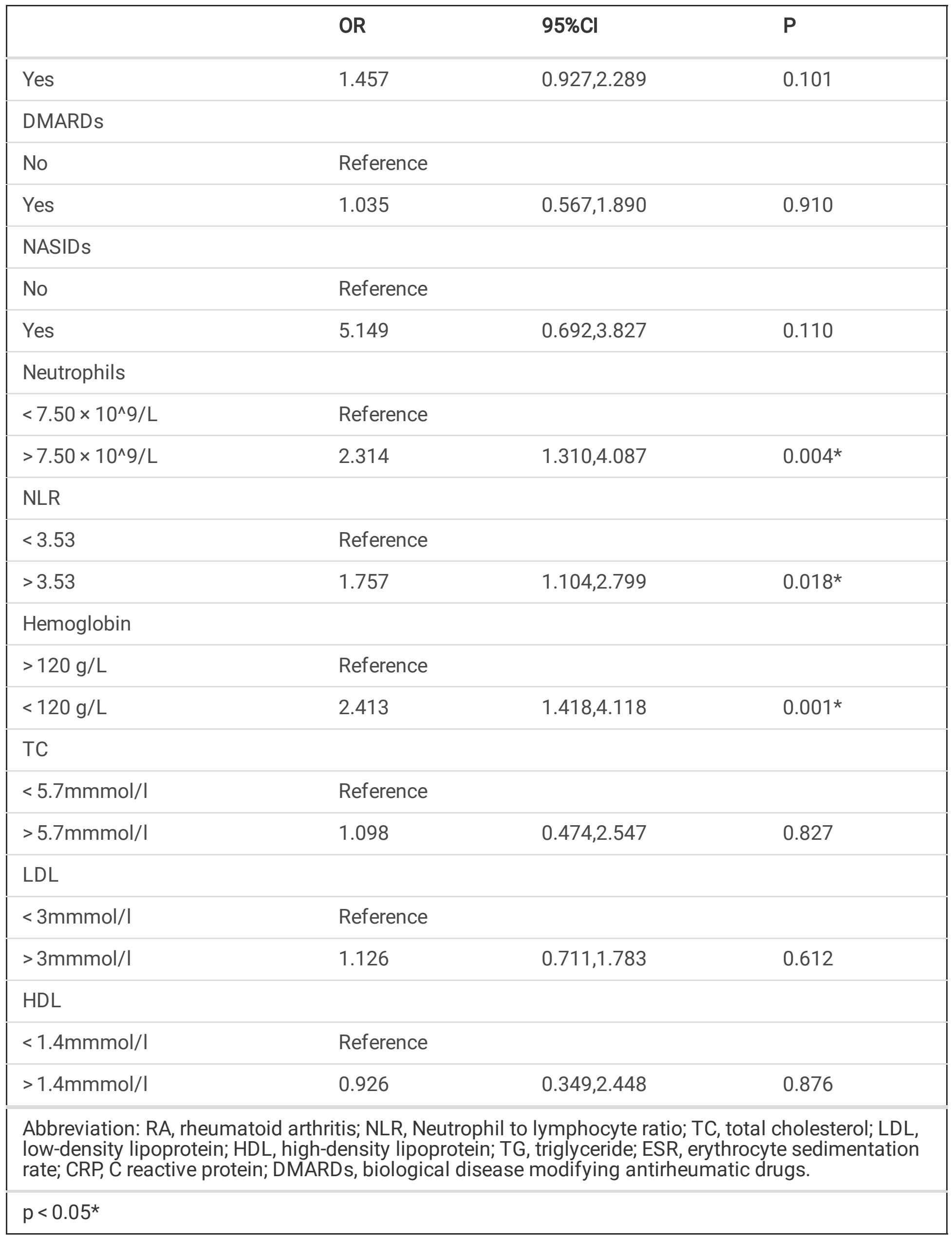




\begin{tabular}{|c|c|c|c|}
\hline & OR & $95 \% \mathrm{Cl}$ & $\mathbf{P}$ \\
\hline \multicolumn{4}{|l|}{ TG } \\
\hline$<1.7 \mathrm{mmmol} / \mathrm{l}$ & \multicolumn{3}{|l|}{ Reference } \\
\hline$>1.7 \mathrm{mmmol} / \mathrm{l}$ & 1.474 & $0.797,2.728$ & 0.216 \\
\hline \multicolumn{4}{|l|}{ ESR } \\
\hline$<15 \mathrm{~mm} / \mathrm{h}$ & \multicolumn{3}{|l|}{ Reference } \\
\hline$>15 \mathrm{~mm} / \mathrm{h}$ & 1.731 & $0.909,3.296$ & 0.095 \\
\hline \multicolumn{4}{|l|}{ CRP } \\
\hline$<10 \mathrm{mg} / \mathrm{L}$ & \multicolumn{3}{|l|}{ Reference } \\
\hline$>10 \mathrm{mg} / \mathrm{L}$ & 1.0444 & $0.620,1.758$ & 0.870 \\
\hline \multicolumn{4}{|l|}{ Uric acid } \\
\hline$<360 \mathrm{umol} / \mathrm{l}$ & \multicolumn{3}{|l|}{ Reference } \\
\hline > 360 umol/l & 6.052 & $3.708,9.878$ & $<0.001^{\star}$ \\
\hline \multicolumn{4}{|c|}{$\begin{array}{l}\text { Abbreviation: RA, rheumatoid arthritis; NLR, Neutrophil to lymphocyte ratio; TC, total cholesterol; LDL, } \\
\text { low-density lipoprotein; HDL, high-density lipoprotein; TG, triglyceride; ESR, erythrocyte sedimentation } \\
\text { rate; CRP, C reactive protein; DMARDs, biological disease modifying antirheumatic drugs. }\end{array}$} \\
\hline \multicolumn{4}{|l|}{$p<0.05^{\star}$} \\
\hline
\end{tabular}

\section{Multivariate logistic regression analysis}

The multivariate logistic regression model was presented in Table 3 and Fig. 4. Age, RA duration, female, CRP, ESR, steroid, NASIDs, NLR, UA level, and hemoglobin were adjusted in the multivariate analysis. Adjusted multivariate analysis showed that neutrophil count $>7.5 \times 10^{\wedge} 9 / \mathrm{L}(\mathrm{OR}=1.754,95 \% \mathrm{Cl}$ : 1.033 to 2.977 ) is significantly associated with higher risk of renal damage in RA patients. We also found that UA $>360$ umol/I (OR $=6.119,95 \% \mathrm{Cl}: 3.708$ to 10.099$)$, Hemoglobin $<120 \mathrm{~g} / \mathrm{L}(\mathrm{OR}=2.412,95 \% \mathrm{Cl}: 1.360$ to 4.281) were strongly correlated with a higher risk of renal impairment in RA patients. 
Table 3

Multivariate logistic regression model for risk factors associated with renal impairment in rheumatoid arthritis

\begin{tabular}{|lll|}
\hline Risk factor in model & OR ${ }^{*}(95 \% \mathrm{Cl})$ & $\mathbf{P}$ \\
\hline Neutrophils $>7.50 \times 10^{\wedge} 9 / \mathrm{L}$ & $1.754(1.033,2.977)$ & 0.037 \\
\hline Hemoglobin $<120 \mathrm{~g} / \mathrm{L}$ & $2.412(1.360,4.281)$ & 0.003 \\
\hline Uric acid $>360 \mathrm{umol} / \mathrm{I}$ & $6.119(3.708,10.099)$ & $<0.001$ \\
\hline $\begin{array}{l}\text { *Odds ratio }(\mathrm{OR}) \text { and } 95 \% \text { confidence interval }(\mathrm{Cl}) \text { obtained from multivariate logistic regression } \\
\text { model. These variables were adjusted in the multivariate analysis: age, duration, female, CRP, ESR, } \\
\text { steroid, NASIDs, NLR, UA, Hemoglobin. }\end{array}$ & \\
\hline
\end{tabular}

\section{Discussion}

In this retrospective cohort study, $14.8 \%$ of patients with RA had a GFR $<60 \mathrm{ml} / \mathrm{min} / 1.73 \mathrm{~m}^{2}$, evaluated using the CKD-EPI formula. Our data are roughly in consistence with findings in previous studies. In a cohort of 400 subjects with RA in England, $13 \%$ had a GFR $<60 \mathrm{ml} / \mathrm{min} / 1.73 \mathrm{~m}^{2}$, estimated by the Modification of Diet in Renal Disease (MDRD) equation [3, 4]. Another cross-sectional study of 107 RA patients and 76 patients with serum-negative arthritis observed renal impairment (GFR $<60 \mathrm{ml} / \mathrm{min}$ $/ 1.73 \mathrm{~m}^{2}$ ) in $17.48 \%$ of the patients with RA [9]. A multicenter cross-sectional survey involving 970 patients in France found that approximately $9 \%$ of patients with RA had impaired renal function, indicated by a GFR $<60 \mathrm{ml} / \mathrm{min} / 1.73 \mathrm{~m}^{2}$ [18].

In this investigation, we found that neutrophil count $>7.5 \times 10^{\wedge} 9 / \mathrm{L}$ was associated with an increased risk of renal damage in RA patients. To our knowledge, this was the first survey to report the relationship between neutrophils and renal damage in RA patients. The property of neutrophils to release extracellular traps was not conducive to the clinical development of RA [19]. It is well-known that a large number of neutrophils accumulate in the synovial tissue of RA, which spontaneously released neutrophil extracellular traps (NETs) [20]. NETs, a network structure consisted of DNA and granulose, could indirectly impair the endothelial function,promote blood vessel and glomerular damage, thus it would induce renal failure and even death [21]. Several previous studies respectively reported that the imbalance between the emergence and removal of NETs adversely affected kidney health $[22,23]$.

Another finding of our present study was that UA $>360 \mathrm{umol} / \mathrm{I}$ and hemoglobin $<120 \mathrm{~g} / \mathrm{L}$ significantly associated with a higher risk of renal impairment in RA patients. Similarly, Daoussis et al. also indicated that an elevated UA level was a strong predictor of renal damage in RA patients [3, 4]. A possible explanation for this relationship may be the reduction of uric acid excretion due to renal dysfunction [24]. Previous studies supported the fact that elevated UA levels affect kidney function by causing renal cortical vasoconstriction, intrarenal vascular disease (hypertension), and renal organ damage [25]. Hyperuricemia played a role in renal vascular injury in healthy rats and kidney-damaged rats, as observed in animal experiments [26]. However, Wolfe et al found that decreased hemoglobin levels were weakly 
associated with renal impairment [27]. Previous studies have demonstrated that decreased hemoglobin levels were more common in patients with CKD [28], which may be due to shortened red blood cell lifespan and iron loss in hemodialysis patients [29, 30], erythropoietin (EPO) deficiency [31], inflammation [32], iron and vitamin deficiency [33,34], or multiple organ dysfunctions [35].

Chiu et al followed more than 12,000 RA patients for five years in a cohort study, and they observed that diabetes, hypertension, hyperlipidemia, and cardiovascular disease were related to renal damage [36], which was consistent with the observations of Couderc et al.[18] and Vansijl et al [14]. Unfortunately, we failed to find an independent link between cardiovascular risk factors and kidney damage. This discrepancy was likely due to the smaller sample size and lack of long-term follow-up in our study. As was found by Haroon et al [9], this study found that corticosteroids, DMARDs and NASIDs usage were not independently associated with kidney damage. Previous evidence showed that the use of NASIDs, methotrexate, tumor necrosis factor (TNF) and DMARDs (such as etanercept) did not add to burden of kidney function of RA patients[37-38], but only long-term use of cyclosporine A and cyclophosphamide caused renal damage in patients with RA [39-40].

Several limitations in this study should be discussed. GFR, estimated by various quantitative equations, has been determined to be the optimal indicator of renal function in recent years. The CKD-EPI SCr/CysC equation recommended as a GRF equation by the KDIGO guidelines [41], has the advantage of more accurate calculated results, narrower calculation error, and broader clinical application $[42,43]$. Therefore, the CKD-EPI equation was chosen to estimate renal function. However, the development of the CKD-EPI $\mathrm{SCr} /$ CysC equation did not take into account differences in race, region, and medical facilities amongst patient cohorts, resulting in potential errors in this study's Chinese cohort in this study [40]. Moreover, the SCr component of the CKD-EPI equation was linked to total muscle mass, and some RA patients also present with sarcopenia. Consequently, CKD-EPI SCr/CysC equations that depend on SCr to assess eGFR may overestimate kidney function in RA patients [44]. Information on the disease progression of RA and the composition of specific medications (such as DMARDs) prescribed to each patient would have improved the estimation of renal function in the cohort of this study, however, missing data disqualified any analysis regarding these two factors in this cohort. In addition, data on urinary protein levels and hematuria, both of which are markers of renal dysfunction, were not collected in the data set. Finally, the vast majority of study participants were Chinese, so the results of this study may not be generalizable to other races. Finally, our survey was a retrospective analysis, and we were unable to clarify the causality.

\section{Conclusion}

In this present study, neutrophil $>7.5 \times 10^{\wedge} 9 / \mathrm{L}$ may be associated with a high risk of renal impairment in RA. We also found that UA $>360 \mathrm{umol} / \mathrm{l}$ and hemoglobin $<120 \mathrm{~g} / \mathrm{L}$ significantly associated with a higher risk of renal impairment in RA patients. Although more prospective studies are needed to verify our results, based on the above data, we believe that continuous monitoring of these risk factors in RA patients is necessary and it could be used for early detection and identification of changes in GFR, allowing doctors to treat patients with potential kidney damage promptly.

Page 11/19 


\section{List Of Abbreviations}

RA: rheumatoid arthritis; GFR: glomerular filtration rate; RR: risk ratio; $95 \% \mathrm{Cl}$ : 95\% confidence interval; UA: uric acid; ESR:erythrocyte sedimentation rate; DMARDs:disease modifying anti-rheumatic drugs; NSAIDs:nonsteroidal anti-inflammatory drugs;TC:total cholesterol; TG: triglycerides; HDL: high-density lipoproteins; LDL:Iow-density lipoproteins; CRP:C-reactive protein levels; WBC:white blood cell; LYM:lymphocyte; NLR: neutrophil to lymphocyte ratio; RBC: red blood cells; HGB:hemoglobin; RF: rheumatoid factor; anti-CCP: anti-cyclic citrullinated peptide; SCr: serum creatinine; CysC:cystatin C; KDIGO: Kidney Disease: Improving Global Outcomes; CKD-EPI: the Chronic Kidney Disease-Epidemiology Collaboration; S.D:standard deviation; IQR:Interquartile range; OR: odds ratio; MDRD:Modification of Diet in Renal Disease; NETs:neutrophil extracellular traps; EPO:erythropoietin.

\section{Declarations}

\section{Ethics approval and consent to participate}

Written informed consent was acquired from all participants. We followed the principles of the Declaration of Helsinki and received approval from the Ethics Committee of the First Affiliated Hospital of Guangzhou University of Traditional Chinese Medicine (No. ZYYECK[2019]040). We had enclosed a statement on ethics approval and consent.

\section{Consent for publication}

Not applicable.

\section{Availability of data and materials}

The datasets during this study are available from the corresponding author on reasonable request.

\section{Competing interests}

We declare that all authors have no conflict of interest.

\section{Funding}

This study was supported in part by: Natural Science Foundation of Guangdong Province (No. 2019A1515011636), Guangzhou science and technology bureau (No. 201904010177), Grant of the First Affiliated Hospital of Guangzhou University of Chinese Medicine (2019QN08), and Guangdong administration of traditional Chinese medicine (No. 20191110). Medical research fund project of Guangdong Province (No. A2020409). 


\section{Authors' contributions}

Pei-Dan Yang, Si-Min Lin and Zhi-Xin Chen contributed in collecting, analyzing the data and drafting the manuscript. Min-Ying Liu and Qing-Ping Liu helped collect the data. Chang-Song Lin conceived of the study. Cong-Qiu Chu ang Qiang Xu conceived of the study, and participated in its design and coordination, and revised this manuscript.

\section{Acknowledgements}

Not applicable.

\section{References}

1. Couderc M, Tatar Z, Pereira B, Tiple A, Gilson M, Fautrel B, et al. Prevalence of Renal Impairment in Patients With Rheumatoid Arthritis: Results From a Cross-Sectional Multicenter Study. Arthritis Care Res. 2016;68(5):638-44.

2. Hickson LTJ, Crowson CS, Gabriel SE, McCarthy JT, Matteson EL. Development of Reduced Kidney Function in Rheumatoid Arthritis. Am J Kidney Dis. 2014;63(2):206-13.

3. Daoussis D, Panoulas VF, Antonopoulos I, John H, Toms TE, Wong P, et al. Cardiovascular risk factors and not disease activity, severity or therapy associate with renal dysfunction in patients with rheumatoid arthritis. Ann Rheum Dis. 2010;69(3):517-21.

4. Daoussis $D$, Panoulas $V$, Toms $T$. Uric acid is a strong independent predictor of renal dysfunction in patients with rheumatoid arthritis. Arthritis Res Ther 2009; 11(4).

5. Sihvonen S, Korpela M, Mustonen J, Laippala P, Pasternack A. Renal Disease as a Predictor of Increased Mortality among Patients with Rheumatoid Arthritis. Nephron Clinical Practice. 2004;96(4):107-14.

6. Al-Aly Z, Zeringue A, Fu J, Rauchman MI, Mcdonald JR, El-Achkar TM, et al. Rate of Kidney Function Decline Associates with Mortality. J Am Soc Nephrol. 1961;21(11):231-7.

7. Karie S, Gandjbakhch F, Janus N, Launay-Vacher V, Rozenberg S, Mai Ba CU, et al. Kidney disease in RA patients: prevalence and implication on RA-related drugs management: the MATRIX study. Rheumatology. 2008;47(3):350-4.

8. Thomas E, Symmons DP, Brewster DH, Black RJ, Macfarlane GJ. National study of cause-specific mortality in rheumatoid arthritis, juvenile chronic arthritis, and other rheumatic conditions: a 20 year followup study. J Rheumatol. 2003;30(5):958-65.

9. Haroon M, ADEEB F, DEVLIN J, O`GRADAIGH D, WALKER F. A comparative study of renal dysfunction in patients with inflammatory arthropathies: strong association with cardiovascular diseases and not with anti-rheumatic therapies, inflammatory markers or duration of arthritis. International Journal of Rheumatic Diseases. 2011;14(3):255-60. 
10. Stuveling EM, Hillege HL, Bakker SJL, Gans ROB, Zeeuw DD. C-reactive protein is associated with renal function abnormalities in a non-diabetic population. Kidney Int. 2003;63(2):654-61.

11. C LF. S, M S. Inflammatory and Prothrombotic Markers and the Progression of Renal Disease in Elderly Individuals. Journal of the American Society of Nephrology Jasn. 2004;15(12):3184-91.

12. Whelton A. Nephrotoxicity of nonsteroidal anti-inflammatory drugs: Physiologic foundations and clinical implications. Am J Med. 1999;106(5):13-24.

13. Raksasuk S, Ungprasert P. Patients with rheumatoid arthritis have an increased risk of incident chronic kidney disease: a systematic review and meta-analysis of cohort studies. Int Urol Nephrol. 2019;52(10):158-61.

14. Van Sijl AM, van den Oever IAM, Peters MJL, Boers M, Dijkmans BAC, van Halm VP, et al. Subclinical renal dysfunction is independently associated with cardiovascular events in rheumatoid arthritis: the CARRE Study. Ann Rheum Dis. 2012;71(3):341-4.

15. Hsien-Yi C, Hui-Ling H, Chien-Hsun L, Hung-An C, Chia-Lun Y, Shih-Hsiang C, et al. Increased Risk of Chronic Kidney Disease in Rheumatoid Arthritis Associated with Cardiovascular Complications - A National Population-Based Cohort Study. Plos One. 2015;10(9):136-8.

16. Levin A, Stevens PE, Bilous RW, Coresh J, Winearls CG. Kidney disease: Improving global outcomes (KDIGO) CKD work group. KDIGO 2012 clinical practice guideline for the evaluation and management of chronic kidney disease. Kidney International Supplements. 2013;3(1):1-150.

17. Shapiro SS, Wilk MB. An analysis of variance test for normality. Biometrika. 1965;52(3):591-9.

18. Couderc M, Tatar Z, Pereira B, Tiple A, Gilson M, Fautrel B, et al. Prevalence of Renal Impairment in Patients With Rheumatoid Arthritis: Results From a Cross-Sectional Multicenter Study. Arthritis Care Research. 2016;68(5):638-44.

19. Weiqian C, Qin W, Yini K, et al. Neutrophil Function in an Inflammatory Milieu of Rheumatoid Arthritis. Journal of immunology research. 2018;4(2):32-5.

20. Chapman EA, Lyon M, Simpson D, Mason D, Beynon RJ, Moots RJ, et al. Caught in a Trap? Proteomic Analysis of Neutrophil Extracellular Traps in Rheumatoid Arthritis and Systemic Lupus Erythematosus. Front Immunol. 2019;10(6):112-5.

21. Salazar-Gonzalez H, Zepeda-Hernandez A, Melo Z, Saavedra-Mayorga DE, Echavarria R. Neutrophil Extracellular Traps in the Establishment and Progression of Renal Diseases. Medicina. 2019;55(8):431-5.

22. Torres-Ruiz J, Villca-Gonzales R, Gómez-Martín D, Zentella-Dehesa A, Alberú J. A potential role of neutrophil extracellular traps (NETs) in kidney acute antibody mediated rejection. Transpl Immunol. 2020;10(2):284-6.

23. Chirivi RGS, Rosmalen JWGV, Linden MVD, Euler M, Raats JMH. ARTICLE Therapeutic ACPA inhibits NET formation: a potential therapy for neutrophil-mediated inflammatory diseases. Cellular molecular immunology. 2020;5(3):99-102.

24. Khosla UM, Zharikov S, Finch JL, Nakagawa T, Roncal C, Mu W, et al. Hyperuricemia induces endothelial dysfunction. Kidney international. 2005;67:1739-46. 
25. Kang DH, Nakagawa T, Feng L, Watanabe S, Johnson R. A role for uric acid in the progression of renal disease. Journal of the American Society of Nephrology Jasn. 2002;13(12):2888-97.

26. Sanchez-Lozada LG, Tapia E, Santamaria J, Avila-Casado C, Soto V, Nepomuceno T, et al. Mild hyperuricemia induces vasoconstriction and maintains glomerular hypertension in normal and remnant kidney rats. Kidney Int. 2005;67(1):237-47.

27. Wolfe F, Michaud K. Anemia and renal function in patients with rheumatoid arthritis. J Rheumatol. 2006;33(8):1516-22.

28. Nurko S. Anemia in chronic kidney disease: Causes, diagnosis, treatment. Cleveland Clinic Journal of Medicine. 2006;73(3):289-97.

29. Tong EM, Nissenson AR. Erythropoietin and anemia. Semin Nephrol. 2001;21(2):190-203.

30. Ly J, Marticorena R, Donnelly S. Red blood cell survival in chronic renal failure. Am J Kidney Dis. 2004;44(4):715-9.

31. Donnelly S. Why is erythropoietin made in the kidney? The kidney functions as a critmeter. American Journal of Kidney Diseases.

32. 2001.; 38(2):415-425.

33. Macdougall IC, Cooper AC. Erythropoietin resistance: the role of inflammation and pro-inflammatory cytokines. Nephrol Dial Transplant. 2002;17(suppl 11):39-43.

34. Besarab A, Frinak S, Yee J. An indistinct balance: the safety and efficacy of parenteral iron therapy. Journal of the American Society of Nephrology Jasn.

35. 1999.; 10(9):2029-2043.

36. Descombes E, Hanck AB, Fellay G. Water soluble vitamins in chronic hemodialysis patients and need for supplementation. Kidney Int. 1993;43(6):1319-28.

37. Eschbach J. The anemia of chronic renal failure: pathophysiology and the effects of recombinant erythropoietin. Contrib Nephrol. 1989;35(1):24.

38. Chiu HY, Cheng Y-P, Tsai T-F. T helper type 17 in psoriasis: From basic immunology to clinical practice. Dermatologica Sinica. 2012;30(4):325-8.

39. Boers M, Croonen AM, Dijkmans BA, et al. Renal findings in rheumatoid arthritis: clinical aspects of 132 necropsies.[J]. Ann Rheum Dis. 1987;46(9):658-63.

40. Nakamura T, Higashi SI, Tomoda K, et al. Etanercept can induce resolution of renal deterioration in patients with amyloid A amyloidosis secondary to rheumatoid arthritis[J]. Clin Rheumatol. 2010;29(12):1395-401.

41. Abraham P, Rabi S, Kulothungan P. Aminoguanidine. Selective Nitric Oxide Synthase Inhibitor, Ameliorates Cyclophosphamide-induced Hemorrhagic Cystitis by Inhibiting Protein Nitration and PARS Activation[J]. Urology. 2009;73(6):1402-6.

42. Sugumar E, Kanakasabapathy I, Abraham P. Normal plasma creatinine level despite histological evidence of damage and increased oxidative stress in the kidneys of cyclophosphamide treated rats[J]. Clin Chim Acta. 2007;376(1-2):244-5. 
43. Andrassy KM. Comments on 'KDIGO 2012 Clinical Practice Guideline for the Evaluation and Management of Chronic Kidney Disease'. Kidney Int. 2013;84(3):622-5.

44. Liu X, Gan X, Chen J, Lv L, Li M, Lou T, et al. A New Modified CKD-EPI Equation for Chinese Patients with Type 2 Diabetes. Plos One. 2014;9(10):743-7.

45. Ma YC, Zuo L, Chen JH, Luo Q, Yu XQ, Li Y, et al. Improved GFR estimation by combined creatinine and cystatin $C$ measurements. Kidney Int. 2008;72(12):1535-42.

46. Pathan E, Joshi VR. Rheumatoid arthritis and the kidney. Assoc Physicians India. 2004;52(9):48894.

47. Peralta CA, Katz R, Sarnak MJ, Ix J, Fried LF, De Boer I, et al. Cystatin C Identifies Chronic Kidney Disease Patients at Higher Risk for Complications. Journal of the American Society of Nephrology Jasn. 2011;22(1):147-55.

\section{Figures}

685 patients meet the classification criteria for rheumatoid arthritis

\section{2 patients $<18$ years old}

81 patients missed critical data for analysis

602 patients were available for analysis

Figure 1 Data Inclusion process

\section{Figure 1}

Data inclusion process 


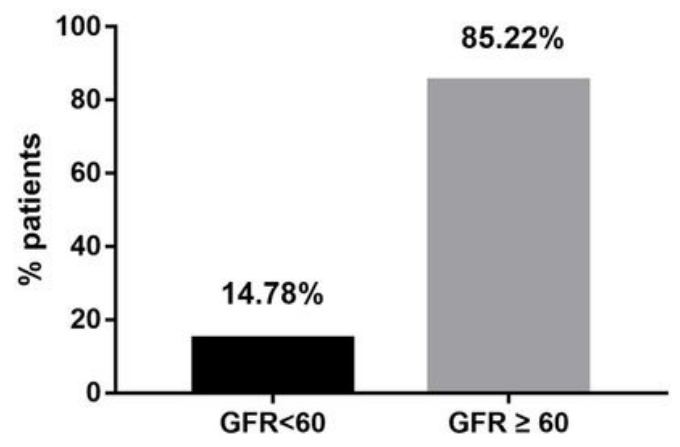

A. Prevalence of renal impairment in rheumatoid arthritis

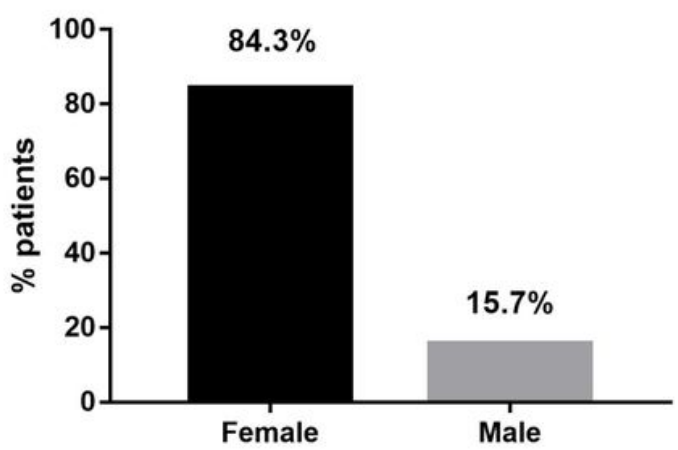

B. Patients with renal impairement

\section{Figure 2}

\section{Figure 2}

A. Prevalence of renal impairment in rheumatoid arthritis; B. Patients with renal impairment 
Figure 3 Univariate logistic regression analysis

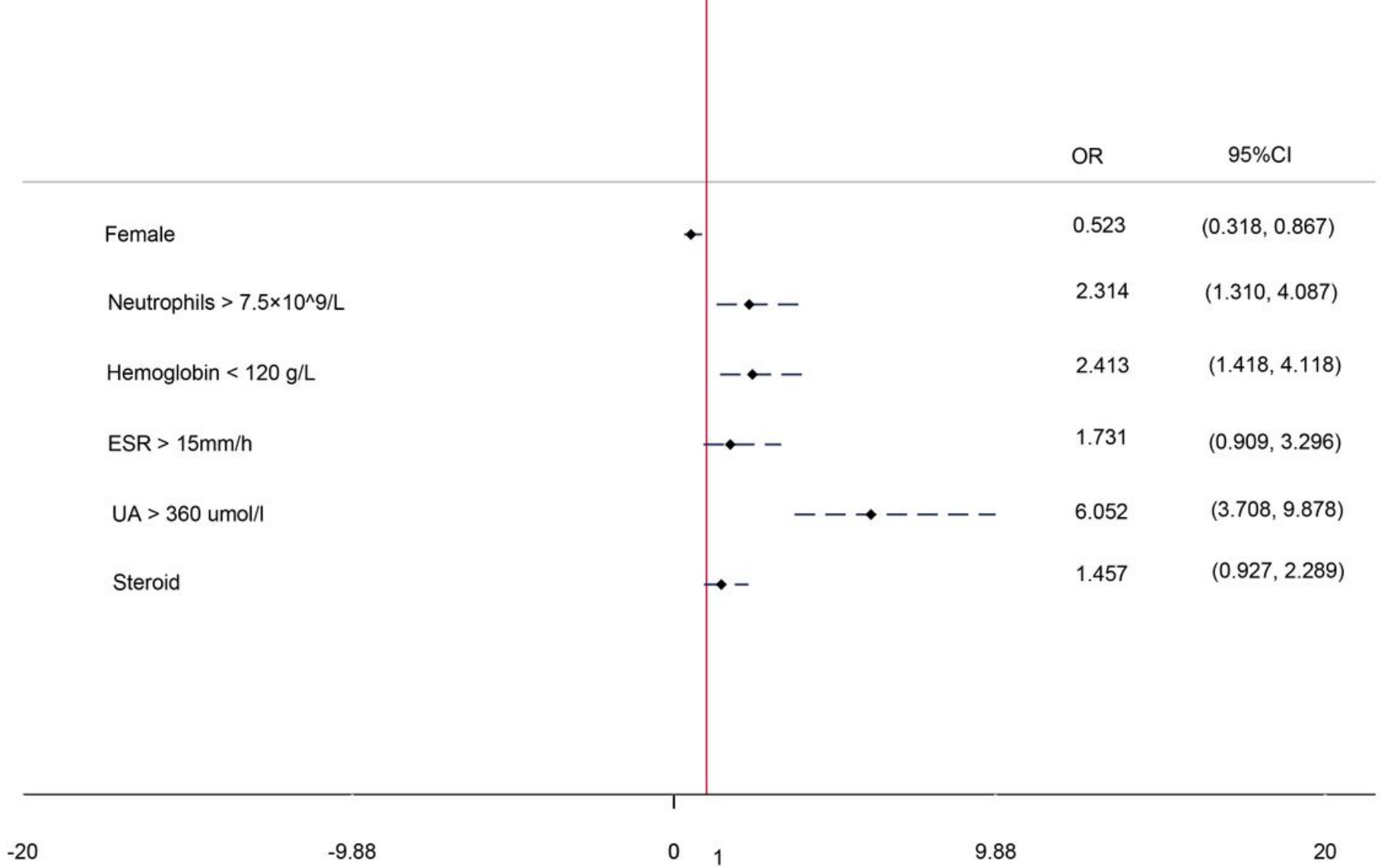

\section{Figure 3}

Forest plots of univariate logistic regression analysis 
Figure 4 Multivariate logistic regression model

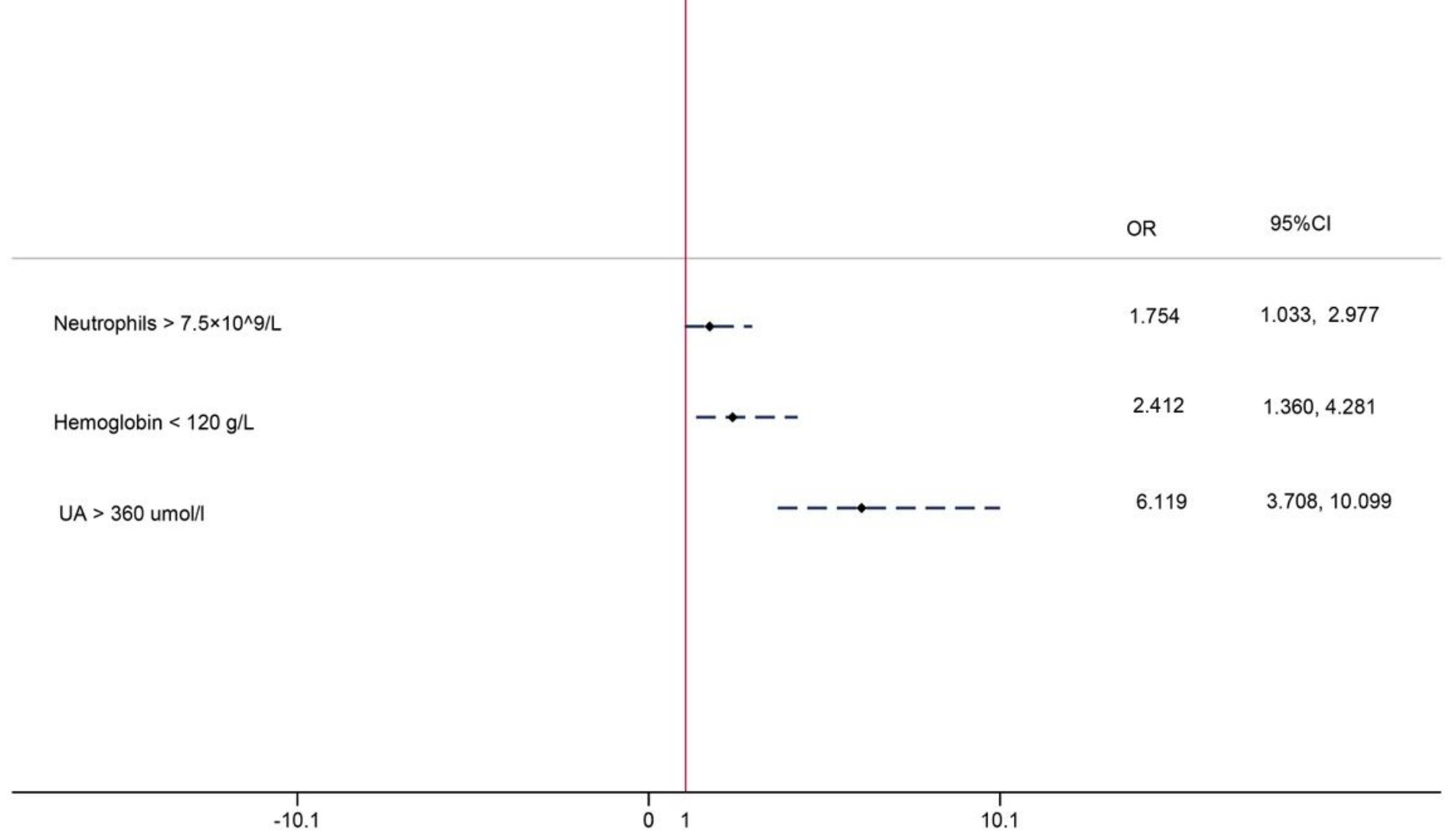

\section{Figure 4}

Forest plots of multivariate logistic regression analysis 